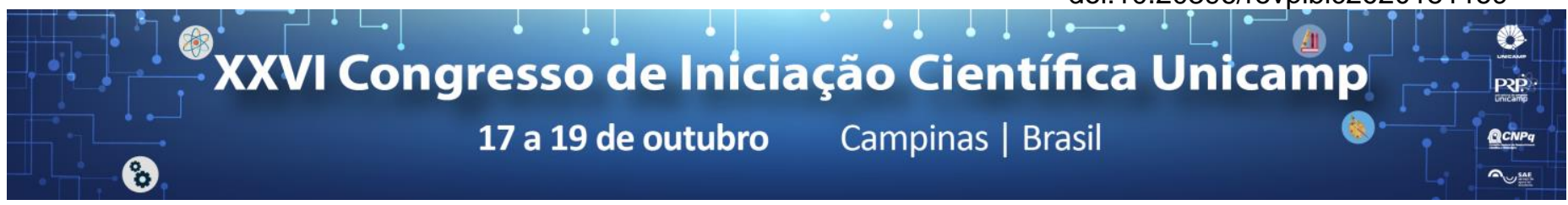

\title{
O input e o output do desenvolvimento de ciência e tecnologia nas instituições públicas de ensino
}

\section{Rafael de Almeida Martarello*, Rafael de Brito Dias.}

\section{Resumo}

Diante do crescente interesse entre cientistas de explorar a caixa-preta do desenvolvimento tecnológico e o interesse de estudo sobre a extensão universitária esta pesquisa analisa aspectos da extensão universitária como fator de interferência para o desenvolvimento tecnológico.

\section{Palavras-chave: \\ Extensão Universitária; Inovação; Unicamp.}

\section{Introdução}

As transferências de tecnologias de inventores ao setor privado têm sido fundamentais para a propagação da potencialidade das invenções, como também para o nascimento da pesquisa tecnológica por empresas. Atualmente a regulamentação permite que universidades comercializassem os direitos de patentes e criem escritórios específicos para a transferência tecnológica. Podemos entender a transferência tecnológica como etapas que transfere invenções feitas por pesquisa científica para organizações produtivas.

Este estudo pretendeu identificar a existência de relação entre os pedidos de patentes e as práticas de atividades de extensão por parte de professores responsáveis pelo desenvolvimento tecnológico. Para isto, foi escolhido como caso o NIT da Universidade Estadual de Campinas e utilizou o recorte para os depósitos de patente de 2014 e o uso do Currículo Lattes de cada pesquisador para obter informações da atividade de extensão executada.

\section{Resultados e Discussão}

A Unicamp é referência nacional no licenciamento de patentes e oferecimento de potencial de mercado para suas patentes. Dentre os registros executados, participaram cerca de $66 \%$ dos institutos da Unicamp, e dentro desta amostra, $46 \%$ dos cientistas realizaram alguma espécie de extensão universitária.

$\mathrm{Em}$ sua maioria os desenvolvedores de patente tem realizado atividade de cursos de extensão, seguido por prestação de serviço de assessoria e consultoria. Outra parte menor dos desenvolvedores se concentraram no item denominado "outros projetos" que abarca: atividades de empreendedorismo, melhoria e atuação na gestão pública e no bem-estar social, programa de cooperação universitária e feiras acadêmicas Por fim, uma pequena parte se concentrou em ações comunitárias.

No cruzamento de dados entre as atividades de extensão que tiveram relação com o desenvolvimento tecnológico por instituto - apresentado na Tabela 1 - podemos inferir que em oito pedidos de patentes teve a influência por parte de atividades de extensão. O total das atividades destes desenvolvedores foram 6 são cursos, entre eles 5 internos e 1 externo. Atividades de prestação de serviços são no total de 5 , enquanto que ação comunitária são duas que resultaram em tecnologias.

De maneira positiva, é notável a quantidade de tecnologias que foram geradas a partir do contato entre cientistas de diferentes institutos da Unicamp, como também de parcerias com demais cientistas.
Tabela 1 Relação entre Patentes e Extensão Universitária

\begin{tabular}{|c|c|c|c|c|}
\hline INSTITUTO & CURSO & $\begin{array}{c}\text { AÇÃO } \\
\text { COMUNITÁRIA }\end{array}$ & $\begin{array}{l}\text { OUTROS } \\
\text { PROJETOS }\end{array}$ & $\begin{array}{l}\text { PRESTAÇÃO } \\
\text { DE SERVIÇO } \\
\end{array}$ \\
\hline CPQBA & 1 & 1 & & 1 \\
\hline FEA & 1 & & 1 & \\
\hline FEEC & 1 & & & 1 \\
\hline FORA & 3 & & & 1 \\
\hline IB & & & 1 & 1 \\
\hline IMECC & & & & 1 \\
\hline Total Geral & 6 & 1 & 2 & 5 \\
\hline
\end{tabular}

Fonte: elaboração própria.

Por outro lado, é evidente o fator encontrado na pesquisa que fortalece a tese da não-linearidade do desenvolvimento técnico, a prioridade de comercialização para grupos de desenvolvedores com notoriedade. A lógica da escolha não está conectada a necessidade do sistema técnico ou a demandas sociais, mas sim condicionada a fatores externos a própria lógica de mercado. Outro resultado visto de forma negativa é o fato de mais da metade dos desenvolvedores não terem empreendido nenhuma prática de extensão universitária ao longo de suas carreiras.

\section{Conclusões}

Aponta-se que atividades externas à medula da pesquisa científica têm refletido sobre o desenvolvimento de tecnologias. No mesmo sentido, a atividade de extensão podem ser consideradas como um fator de colaboração para o desenvolvimento tecnológico.

Ademais este estudo permite continuidade a partir de dois caminhos, o primeiro é realizar entrevistas com cientistas responsáveis pelo desenvolvimento tecnológico para aprofundamento do entendimento sobre o processo criativo, e o segundo analisar anos anteriores para realizar afirmativas mais fortes sobre a relação entre as atividades estudadas.

\section{Agradecimentos}

Ao PIBIC/CNPq Instituição de fomento desta pesquisa. 